\title{
PENSION FUNDING AND THE ACTUARIAL ASSUMPTION CONCERNING INVESTMENT RETURNS
}

\author{
BY
}

\author{
M. IQBAL OWADALLY
}

\begin{abstract}
An assumption concerning the long-term rate of return on assets is made by actuaries when they value defined-benefit pension plans. There is a distinction between this assumption and the discount rate used to value pension liabilities, as the value placed on liabilities does not depend on asset allocation in the pension fund. The more conservative the investment return assumption is, the larger planned initial contributions are, and the faster benefits are funded. A conservative investment return assumption, however, also leads to long-term surpluses in the plan, as is shown for two practical actuarial funding methods. Long-term deficits result from an optimistic assumption. Neither outcome is desirable as, in the long term, pension plan assets should be accumulated to meet the pension liabilities valued at a suitable discount rate. A third method is devised that avoids such persistent surpluses and deficits regardless of conservatism or optimism in the assumed investment return.
\end{abstract}

\section{KEYWORDS}

Actuarial valuation, funding method, intervaluation gains and losses.

\section{INTRODUCTION}

Actuaries periodically value defined benefit pension plans to recommend suitable contribution rates. A number of valuation assumptions are made for this purpose concerning various uncertain factors affecting the value of pension obligations and the funding for these obligations. This set of valuation assumptions is usually called the valuation basis. Different bases may be required for different purposes. For example, in certain jurisdictions, technical solvency bases may be specified by regulation. There may also be a different set of projection assumptions, usually scenario-based or stochastic, to investigate pension benefit amendments, asset-liability management or other issues.

Actuarial valuations for funding purposes, that is, with the objective of recommending a contribution rate are considered in this paper. A deterministic valuation basis is typically employed. Factors of a demographic nature about 
which assumptions are made include the mortality of plan participants at various ages, as well as their disability and withdrawal rates from the plan. Assumptions about economic factors such as price and wage inflation are also required when pensions are a function of final or career-average salary and when they are indexed with price inflation. An assumption about investment returns on the pension plan assets is also made.

If the pension liability exceeds the plan assets, then an unfunded liability (or deficit) exists. The unfunded liability varies over time as actual experience generally does not unfold exactly according to actuarial valuation assumptions. Suitable methods of pension funding generate a schedule of contributions that satisfies two objectives. First, unfunded liabilities must be paid off and there must be enough funds to pay benefits as and when they are due. Second, the contributions that are required from the sponsor and members of the plan must be stable over time.

In this paper, we investigate the effect on pension funding of deviation of actual experience from the actuarial investment return assumption. The relevance of this assumption is discussed in section 2. A simple model is described in section 3. It is used to investigate pension funding under two common funding methods, in sections 4 and 5, and under a variation described in section 6 which has the useful property of yielding full funding independently of the investment return assumption. Finally, a numerical example is given in section 7.

A list of important symbols is given here for ease of reference:

$A L \quad$ actuarial liability

$B \quad$ benefit paid every year

$C_{t} \quad$ pension contribution paid at start of year $(t, t+1)$

$F_{t} \quad$ market value of pension plan assets at time $t$

$i \quad$ actual rate of return on plan assets

$i_{A} \quad$ actuarial assumption for rate of return on plan assets

$i_{L} \quad$ actuarial assumption for rate to discount pension liabilities

$K \quad$ parameter in spreading of gains and losses (equation (20))

$K_{1}, K_{2} \quad$ parameters in modified spreading of gains and losses (equation (36))

$L_{t} \quad$ actuarial intervaluation loss in year $(t-1, t)$

$m \quad$ amortization period for gains and losses in section 4 (equation (13))

$n \quad$ amortization period for initial unfunded liability (equation (10))

$N C \quad$ normal cost or normal contribution rate

$P_{t} \quad$ payment for initial unfunded liability at time $t$ (equation (10))

$S_{t} \quad$ supplementary contribution paid at the start of year $(t, t+1)$

$u, u_{A}, u_{L} 1+i, 1+i_{A}, 1+i_{L}$ respectively

$U_{t} \quad$ unamortized part of initial unfunded liability at time $t$ (equation (11))

$U L_{t} \quad$ unfunded liability $=A L-F_{t}$

$v, v_{A}, v_{L} \quad(1+i)^{-1},\left(1+i_{A}\right)^{-1},\left(1+i_{L}\right)^{-1}$ respectively 


\section{InVEstment Return Assumption}

The actuarial investment return assumption, henceforth denoted by $i_{A}$, is an assumption concerning the long-term rate of return on pension plan assets. Funding for pension benefits involves the substitution of contribution income (from plan participants and sponsor) by investment income from accumulated assets. It is well-known that the choice of $i_{A}$ (and indeed of other valuation assumptions) affects the incidence of contribution payments and pace of funding: see for example Berin (1989, p. 93) and Trowbridge and Farr (1976, p. 27). The more optimistic the investment return assumption is, the larger the investment return is assumed to be in any given year, and the smaller the contribution that is initially required. If insufficient assets are eventually accumulated compared to the pension liability (that is, if a deficit emerges), then higher contributions than otherwise necessary will eventually be required. Conversely, the more conservative $i_{A}$ is, the larger the contribution that is initially required and, if surpluses emerge, smaller contributions than otherwise necessary, will eventually be required. Thus, the schedule of contribution payments is accelerated the more $i_{A}$ is conservative, and it is slowed down the more $i_{A}$ is optimistic. The actuarial choice of $i_{A}$ is therefore a means of controlling the pace of funding in the pension plan (Daykin, 1976; Trowbridge and Farr, 1976, p. 27).

Another key actuarial valuation assumption is the interest rate assumption $\left(i_{L}\right)$ used to discount pension liabilities. As pension liabilities are not generally traded, they must be priced by comparison with similar asset cash flows. In theory, pension liabilities should be valued using market discount rates, suitably risk-adjusted, or at the rates implied in asset portfolios that are dedicated or matched by cash flow to these liabilities. In practice, more approximate methods are used. Pension liabilities have a long duration and are usually discounted at a single term-independent discount rate which is typically based on corporate bond yields to reflect the risk of default from the sponsor.

In classical actuarial valuation methodology (for example, Trowbridge and Farr, 1976), $i_{A}$ and $i_{L}$ are identical. More recent actuarial practice distinguishes between the two assumptions: see for example Actuarial Standard of Practice No. 27 of the Actuarial Standards Board (1996) in the United States. The U.S. pension accounting standard FAS87 also distinguishes between the liability discount rate and the assumption for the "expected long-term rate of return on plan assets". Thornton and Wilson (1992) refer to a "dual-interest" valuation method, used in the United Kingdom, whereby $i_{A}$ is a "best-estimate assumption" of investment return on the actual asset portfolio and $i_{L}$ is a "prudent estimate" of investment return based on a hypothetical asset portfolio that matches pension liabilities.

The distinction between the pension liability discount rate assumption and the investment return assumption is often blurred in practice because it is assumed that they are numerically equal. Actuarial Standard of Practice No. 27 of the U.S. Actuarial Standards Board (1996) states that "generally, the appropriate discount rate is the same as the investment return assumption". This presumes that the pension fund is invested in assets that closely match or hedge or 
immunize the pension liability so that approximately equal discount rates apply to both asset and liability cash flows. In practice, asset allocation may involve a mismatch between assets and liabilities. For example, asset managers may have a rate-of-return objective involving a benchmark portfolio or index set without reference to the liabilities (McGill et al., 1996, p. 659). It is also generally difficult to hedge pension liabilities perfectly with normal market instruments, because of the risk of default from the plan sponsor and because final-salary pensions are related to economic wage inflation.

In this paper, the assumed rates on assets and liabilities $\left(i_{A}\right.$ and $i_{L}$ respectively) are taken to be conceptually distinct (although they could be numerically equal). The aim of this paper is to investigate the effect on pension funding of actual investment returns being different from the assumed investment return on assets.

\section{Model}

A simplified model of a defined benefit pension plan is used here. For details of the model, refer to Dufresne $(1988,1989)$ and Owadally and Haberman (1999). A stationary pension plan population is assumed, with fixed mortality and withdrawal rates at different ages. The only benefit that is provided in the model plan is a final-salary pension paid at normal retirement age. There is no inflation on salaries and it is also postulated that actuarial valuation assumptions remain unchanged over time. This leads to a significant simplification in that the payroll, the pension benefit $B$ paid out every year, as well as the combination of actuarial liability $A L$ and normal cost $N C$ generated by a given actuarial cost method, are constant. Trowbridge (1952) shows that an equation of equilibrium holds:

$$
A L=\left(1+i_{L}\right)(A L+N C-B),
$$

where $i_{L}$ is the interest rate used to discount pension liability cash flows. (Alternatively, one may assume that benefits in payment are indexed with wage inflation so that, when measured net of wage inflation, the payroll as well as $B, A L$ and $N C$ are all constant. All quantities must then be considered net of wage inflation).

Assuming that contributions $C_{t}$ and benefits $B$ are paid at the start of year $(t, t+1)$, the value of the pension fund $F_{t}$ at time $t$ follows a simple recurrence relation:

$$
F_{t+1}=(1+i)\left(F_{t}+C_{t}-B\right),
$$

where $i$ is the actual rate of return earned on the pension plan assets. The unfunded liability is defined as the excess of actuarial liability over assets:

$$
U L_{t}=A L-F_{t} .
$$

It is assumed that all actuarial valuation assumptions, other than $i_{A}$, are borne out by experience. In other words, demographic and economic experience 
unfold in accordance with actuarial valuation assumptions, except that the actual investment rate of return $i$ may differ from the assumed investment rate of return $i_{A}$.

An intervaluation loss $L_{t}$ during year $(t, t+1)$ is the change in unfunded liability as a result of actual experience deviating from actuarial valuation assumptions (Dufresne, 1989). A gain is defined as a negative loss. More specifically, an asset loss is the unexpected increase in unfunded liability that is attributable to the actual investment return being less than the investment return assumption. The contribution that is paid at the start of year $(t, t+1)$ is equal to the normal cost $N C$ plus a supplementary contribution $S_{t}$ which is paid to amortize past intervaluation losses and any initial unfunded liability:

$$
C_{t}=N C+S_{t} .
$$

Letting $v_{L}=\left(1+i_{L}\right)^{-1}$, it follows from equations (1)-(4) that

$$
U L_{t+1}=A L+(1+i)\left(U L_{t}-S_{t}-v_{L} A L\right) .
$$

Actual experience does not deviate from actuarial assumptions except possibly in investment returns. Therefore, only asset gains or losses occur. An expression for the asset loss is obtained by Dufresne (1989) as follows. Had a rate of return of $i_{A}$ been earned on the plan assets (instead of the actual rate of return $i$ ), the unfunded liability at the end of year $(t, t+1)$ would have been $U L_{t+1}^{A}=A L+$ $\left(1+i_{A}\right)\left(U L_{t}-S_{t}-v_{L} A L\right)$, by comparison with equation (5). Therefore the intervaluation loss in year $(t, t+1)$ is

$$
\begin{aligned}
L_{t+1} & =U L_{t+1}-U L_{t+1}^{A} \\
& =U L_{t+1}-A L-\left(1+i_{A}\right)\left(U L_{t}-S_{t}-v_{L} A L\right) \\
& =\left(i-i_{A}\right)\left(U L_{t}-S_{t}-v_{L} A L\right) .
\end{aligned}
$$

Equation (8) shows that the asset intervaluation loss $L_{t+1}$ in year $(t, t+1)$ arises because the actual return on assets in that year $(i)$ is different from the assumed return $\left(i_{A}\right)$. Equation (7) may be rewritten as

$$
U L_{t+1}-u_{A} U L_{t}=L_{t+1}-u_{A}\left(S_{t}-\left(v_{A}-v_{L}\right) A L\right),
$$

where $u_{A}=1+i_{A}$ and $v_{A}=\left(1+i_{A}\right)^{-1}$.

The supplementary contribution $S_{t}$ in equation (4) pays off over time past intervaluation losses as well as any initial unfunded liability at time 0 . The initial unfunded liability may arise because of past service liabilities, or because of a change in the valuation basis or an amendment to benefit rules.

Assume henceforth that $L_{t}=0$ for $t \leq 0, U L_{t}=0$ for $t<0$, and that the initial unfunded liability $U L_{0}$ is amortized over a finite period of $n$ years at rate $i_{A}$ by means of payments 


$$
P_{t}= \begin{cases}U L_{0} / \ddot{a}_{\bar{n} \mid}, & 0 \leq t \leq n-1 \\ 0, & t \geq n\end{cases}
$$

In equation (10), $\ddot{a}_{\bar{n} \mid}=\left(1-v_{A}^{n}\right) /\left(1-v_{A}\right)$ denotes the present value of an annuitycertain of term $n$ payable in advance and calculated at rate $i_{A}$. The unamortized part of the initial unfunded liability at time $t$ is

$$
U_{t}= \begin{cases}U L_{0} \ddot{a}_{\overline{n-t \mid}} / \ddot{a}_{\bar{n} \mid}, & 0 \leq t \leq n-1, \\ 0, & t \geq n .\end{cases}
$$

Observe that

$$
u_{A} U_{t}-U_{t+1}=u_{A} P_{t} .
$$

\section{Amortizing GAINS AND Losses}

Dufresne (1989) describes a funding method whereby the supplementary contribution $S_{t}$, in equation (4), is calculated to amortize past intervaluation gains and losses. His analysis may be extended by allowing for a distinction between the liability valuation rate $\left(i_{L}\right)$ and the investment return assumption $\left(i_{A}\right)$, as well as by explicitly amortizing the initial unfunded liability:

$$
S_{t}=\sum_{j=0}^{m-1} \frac{L_{t-j}}{\ddot{a}_{\bar{m}}}+\left(v_{A}-v_{L}\right) A L+P_{t} .
$$

In equation (13), $\ddot{a}_{\bar{m} \mid}=\left(1-v_{A}^{m}\right) /\left(1-v_{A}\right)$ is the present value of an annuitycertain over $m$ years payable in advance and calculated at assumed rate $i_{A}$. The supplementary contribution consists of level amortization payments for intervaluation losses over the past $m$ years, an adjustment for the difference between assumed rates on assets and liabilities, as well as an amortization payment for the initial unfunded liability.

Replacing $S_{t}$ from equation (13) into equation (9) and using equation (12) yields

$$
\left(U L_{t+1}-U_{t+1}\right)-u_{A}\left(U L_{t}-U_{t}\right)=L_{t+1}-u_{A} \sum_{j=0}^{m-1} \frac{L_{t-j}}{\ddot{a}_{\bar{m} \mid}} .
$$

The unfunded liability at the end of the year is therefore the accumulation of the unfunded liability at the start of the year plus the loss that emerges during the year less the accumulated value of payments made in respect of past losses.

It is easily verified that the solution of equation (14) is

$$
U L_{t}-U_{t}=\sum_{j=0}^{m-1} \frac{\ddot{a}_{\overline{m-j \mid}}}{\ddot{a}_{\bar{m} \mid}} L_{t-j}
$$


For details of this solution, see Dufresne (1989). Note also equation (12) for the initial unfunded liability and recall that the annuities are valued at rate $i_{A}$.

When the funding method in equation (13) is used, a unit loss that emerged $j$ years ago is completely paid off if $j \geq m$, but further payments of $1 / \ddot{a}_{\bar{m}}$ for the next $m-j$ years are outstanding if $0 \leq j \leq m-1$. The present value of these payments is $\ddot{a}_{\bar{m}-j l} / \ddot{a}_{\bar{m} \mid}$. Equation (15) shows that the unfunded liability is the present value of the payments that remain to be made in respect of losses that are not yet paid off, together with the unamortized part of the initial unfunded liability.

As in Dufresne (1989), replace $S_{t}$ from equation (13) and $U L_{t}$ from equation (15) into equation (8), and use equation (12), to obtain:

$$
L_{t+1}=\left(i-i_{A}\right)\left[\sum_{j=0}^{m-1} L_{t-j}\left(\ddot{a}_{\overline{m-j \mid}}-1\right) / \ddot{a}_{\overline{m \mid}}-v_{A}\left(A L-U_{t+1}\right)\right] .
$$

If the actual rate of return on plan assets in a given year is the same as the assumed rate of return (that is, if $i=i_{A}$ ), no intervaluation loss emerges in that year $\left(L_{t}=0 \forall t\right.$ from equation (16)) and the unfunded liability consists only of the unamortized part of the initial unfunded liability $\left(U L_{t}=U_{t}\right.$ for $t \geq 0$ from equation (15)).

Dufresne (1989) obtains a sufficient condition for the convergence of $\left\{L_{t}\right\}$, $\left\{U L_{t}\right\}$ and $\left\{S_{t}\right\}$ as $t \rightarrow \infty$. The following result is due to Dufresne (1989).

RESUlt 1. Provided that $\left|i-i_{A}\right| \sum_{j=0}^{m-1}\left(\ddot{a}_{\overline{m-j \mid}}-1\right) / \ddot{a}_{\bar{m} \mid}<1$,

$$
\begin{aligned}
& \lim _{t \rightarrow \infty} L_{t}=\frac{-\left(i-i_{A}\right) v_{A} A L}{1-\left(i-i_{A}\right) \sum_{j=0}^{m-1}\left(\ddot{a}_{\overline{m-j \mid}}-1\right) / \ddot{a}_{\bar{m} \mid}}, \\
& \lim _{t \rightarrow \infty} U L_{t}=\sum_{j=0}^{m-1} \frac{\ddot{a}_{\overline{m-j \mid}}}{\ddot{a}_{\bar{m} \mid}} \lim _{t \rightarrow \infty} L_{t}, \\
& \lim _{t \rightarrow \infty} S_{t}=\frac{m}{\ddot{a}_{\bar{m} \mid}} \lim _{t \rightarrow \infty} L_{t}+\left(v_{A}-v_{L}\right) A L .
\end{aligned}
$$

The only differences between (17)-(19) and the results of Dufresne (1989) are that the annuities are valued at rate $i_{A}$ here and there is an explicit term for the difference between $i_{A}$ and $i_{L}$ in equation (19). Equations (17)-(19) follow from equations (16), (15) and (13). (Recall that $U_{t}=0$ for $t \geq n$ from equation (11) since the initial unfunded liability is amortized over a finite period $n$.)

COROLlarY 1. Assume that $\left|i-i_{A}\right| \sum_{j=0}^{m-1}\left(\ddot{a}_{\overline{m-j l}}-1\right) / \ddot{a}_{\bar{m} \mid}<1$.

If $i_{A}=i$, then $\lim U L_{t}=0$. If $i_{A}>i$, then $\lim U L_{t}>0$. If $i_{A}<i$, then $\lim U L_{t}<0$.

Corollary 1 confirms the observations made in section 2 : if the actuarial investment return assumption is optimistic (that is, $i_{A}>i$ ), then a persistent 
deficit occurs $\left(\lim U L_{t}>0\right)$; on the other hand, if the investment return assumption is conservative (that is, $\left.i_{A}<i\right)$, then a persistent surplus occurs $\left(\lim U L_{t}<0\right)$. Note also that, if $i_{A} \neq i, \lim U L_{t}$ depends on the period $m$ over which gains and losses are amortized.

\section{Spreading Gains and Losses}

Dufresne (1988) discusses another funding method that is used to determine contributions. This method is widely used in the United Kingdom and is also implicit in actuarial cost methods such as the Aggregate and Frozen Initial Liability methods (Trowbridge and Farr, 1976, p. 85). The equations in Dufresne (1988) may also be extended to allow for the distinction between the rate at which liabilities are discounted and the investment return assumption, as well as for the separate treatment of the initial unfunded liability.

The supplementary contribution paid in year $(t, t+1)$ is

$$
S_{t}=\sum_{j=0}^{\infty}(1-K) K^{j} u_{A}^{j} L_{t-j}+\left(v_{A}-v_{L}\right) A L+P_{t},
$$

where $0 \leq K<v_{A}$. In this alternative method, a unit loss is paid off by means of a sequence of exponentially declining payments, $\left\{(1-K) K^{j} u_{A}^{j}, j=0,1, \ldots\right\}$, the unit loss being paid off in perpetuity since $\sum_{j=0}^{\infty}(1-K) K^{j} u_{A}^{j} \cdot v_{A}^{j}=1$. The larger the parameter $K$, the slower the loss is paid off. The loss is never completely defrayed, except in the limit as $t \rightarrow \infty$, but Trowbridge and Farr (1976) point out that this is not a weakness as intervaluation losses occur randomly in practice and are never completely removed. This funding method is commonly referred to as "spreading" gains and losses, by contrast with the method in section 4 which involves amortizing gains and losses (McGill et al., 1996, p. 525; Berin, 1989, p. 18; Dufresne, 1988). yields

Replacing $S_{t}$ from equation (20) into equation (9) and using equation (12)

$$
\left(U L_{t+1}-U_{t+1}\right)-u_{A}\left(U L_{t}-U_{t}\right)=L_{t+1}-u_{A} \sum_{j=0}^{\infty}(1-K) K^{j} u_{A}^{j} L_{t-j} .
$$

Recall that $L_{t}=0$ for $t \leq 0, U L_{t}=0$ for $t<0$, and $U L_{0}=U_{0}$. It is easily verified, from equation (21), that

$$
U L_{t}-U_{t}=\sum_{j=0}^{\infty} K^{j} u_{A}^{j} L_{t-j}
$$

Compare equation (15) when losses are amortized to equation (22) when losses are spread.

Equation (22) is sensible since, for a unit loss that emerged $j$ years ago, the following sequence of payments is outstanding: $\left\{(1-K) K^{l} u_{A}^{l}, l=j, j+1, \ldots\right\}$. 
The present value of these payments is $\sum_{l=j}^{\infty}(1-K) K^{l} u_{A}^{l} \cdot v_{A}^{l-j}=K^{j} u_{A}^{j}$. Equation (22) thus shows that, at any time $t$, the unfunded liability is the present value of payments yet to be made in respect of all past and present losses, together with the unamortized part of the initial unfunded liability.

The supplementary contribution $S_{t}$ in this method may be calculated directly as a proportion $1-K$ of the unfunded liability, together with an adjustment for the difference between assumed rates on assets and liabilities and for the separate amortization of the initial unfunded liability. Comparing equations (20) and (22),

$$
S_{t}=(1-K)\left(U L_{t}-U_{t}\right)+\left(v_{A}-v_{L}\right) A L+P_{t} .
$$

For simplicity, Dufresne (1988) disregards the separate treatment of initial unfunded liability and the distinction between $i_{A}$ and $i_{L}$ and considers only $S_{t}=(1-K) U L_{t}$. Dufresne (1988) also states that the parameter $K$ is usually calculated as $K=1-1 / \ddot{a}_{\bar{M}}$. $M$ is typically between 1 and 10 years in the United Kingdom. Thus, if $M=m$, the first payment made in respect of a unit loss is $1 / \ddot{a}_{\bar{m} \mid}$ under both the amortization and spreading funding methods (equations (13) and (20) respectively).

Replace $S_{t}$ from equation (20) and $U L_{t}$ from equation (22) into equation (8), and use equation (12), to obtain:

$$
L_{t}=\left(i-i_{A}\right)\left[\sum_{j=0}^{\infty} K^{j+1} u_{A}^{j} L_{t-j}-v_{A}\left(A L-U_{t+1}\right)\right] .
$$

Compare equation (16) when losses are amortized to equation (24) when losses are spread. If the actuarial assumption as to the rate of investment return on plan assets equals the actual rate of return (that is, if $i=i_{A}$ ), then no loss emerges $\left(L_{t}=0 \forall t\right.$ from equation (24)) and the unfunded liability consists only of the unamortized part of the initial unfunded liability $\left(U L_{t}=U_{t}\right.$ for $t \geq 0$ from equation (22)).

From equation (24),

$$
L_{t+1}-u_{A} K L_{t}=\left(i-i_{A}\right)\left[K L_{t}-v_{A}\left(A L-U_{t+1}\right)+K\left(A L-U_{t}\right)\right],
$$

which is a first-order linear difference equation that simplifies to

$$
L_{t+1}-u K L_{t}=-v_{A}\left(i-i_{A}\right)\left[\left(A L-U_{t+1}\right)-u_{A} K\left(A L-U_{t}\right)\right] .
$$

Recall from equation (11) that $U_{t}=0$ for $t \geq n$. Provided $|u K|<1$, it follows from equation (26) that

$$
\lim _{t \rightarrow \infty} L_{t}=-A L\left(i-i_{A}\right) v_{A} \frac{1-u_{A} K}{1-u K} .
$$

In equation (20), $K$ was defined to be such that $0 \leq K<v_{A}$. Provided $|u K|<1$, the right hand side of equation (22) is also absolutely convergent and 


$$
\lim _{t \rightarrow \infty} U L_{t}=\left(1-u_{A} K\right)^{-1} \lim _{t \rightarrow \infty} L_{t}
$$

$\lim S_{t}$ may be found from equations (23) and (28). This is summarised in the following result.

ReSUlt 2 Provided $|u K|<1$,

$$
\begin{aligned}
& \lim _{t \rightarrow \infty} L_{t}=-A L\left(i-i_{A}\right) v \frac{v_{A}-K}{v-K}, \\
& \lim _{t \rightarrow \infty} U L_{t}=A L \frac{v-v_{A}}{v-K}, \\
& \lim _{t \rightarrow \infty} S_{t}=A L(1-K) \frac{v-v_{A}}{v-K}+A L\left(v_{A}-v_{L}\right) .
\end{aligned}
$$

In contrast with Dufresne (1988), we have allowed for separate amortization of the initial unfunded liability and also for the possibility that the actuarial assumptions $i_{A}$ and $i_{L}$ are different, and we have also derived equations pertaining to the intervaluation loss $L_{t}$. Result 2 may alternatively be obtained, as in Dufresne (1988), by substituting $S_{t}$ from equation (23) into equation (5) giving a first-order difference equation

$$
\left(U L_{t+1}-U_{t+1}\right)-u K\left(U L_{t}-U_{t}\right)=\left(1-u v_{A}\right)\left(A L-U_{t+1}\right),
$$

which solves to

$$
U L_{t}-U_{t}=\left(1-u v_{A}\right) \sum_{j=0}^{t-1}(u K)^{j}\left(A L-U_{t-j}\right) .
$$

Corollary 2 hereunder follows directly from equation (30):

Corollary 2 Assume that $|u K|<1$. If $i_{A}=i$, then $\lim U L_{t}=0$. If $i_{A}>i$, then $\lim U L_{t}>0$. If $i_{A}<i$, then $\lim U L_{t}<0$.

Compare Corollary 1 with Corollary 2. Under both amortization and spreading, the choice of the actuarial investment return assumption $i_{A}$ affects the long-term funding status of the pension plan. Note also from equation (30) that, when $i_{A} \neq i, \lim U L_{t}$ depends on the parameter $K$ that is used to spread gains and losses.

\section{Modified Spreading of Gains And Losses}

If the actual investment return deviates from the actuarial investment return assumption, then persistent underfunding or overfunding will occur in the long term, as shown in Corollaries 1 and 2 in both of the preceding methods. Persistent deficits jeopardize the security of pension benefits for plan members 
since, in the event of sponsor insolvency, there will not be enough funds to meet benefit obligations. On the other hand, excessive surpluses are also undesirable as funds are being diverted from productive activity in the company. Plan participants may also demand that surpluses be distributed to them in the form of improved benefits (McGill et al., 1996, p. 592-4).

In practice, the emergence of persistent surpluses or deficits causes actuaries to revise their actuarial valuation assumptions. Nevertheless, it is of interest to devise a funding method that avoids systematic surpluses and deficits.

Suppose that a constant stream of intervaluation losses of size $l>0$ occurs in the pension plan. If losses are being amortized as in the method of section 4 , then a positive unfunded liability (that is, a deficit) occurs since, from equation (15) and for $t \geq n$,

$$
U L_{t}=\ell \sum_{j=0}^{m-1} \frac{\ddot{a}_{\overline{m-j l}}}{\ddot{a}_{\bar{m} \mid}}>0 .
$$

Likewise, a deficit occurs if losses are being spread, as in section 5 , since, from equation (22) and for $t \geq n$,

$$
U L_{t}=\ell /\left(1-u_{A} K\right)>0 .
$$

This suggests a variation on the spreading of losses. Consider a new funding method, which is referred to henceforth as "modified spreading of gains and losses", where supplementary contributions are calculated to pay off intervaluation losses and the initial unfunded liability as follows:

$$
S_{t}=\sum_{j=0}^{\infty}\left(\alpha_{1} K_{1}^{j}-\alpha_{2} K_{2}^{j}\right) u_{A}^{j} L_{t-j}+\left(v_{A}-v_{L}\right) A L+P_{t}
$$

where

$$
\begin{gathered}
\alpha_{1}=\left(1-u_{A} K_{1}\right)\left(1-K_{1}\right) / u_{A}\left(K_{2}-K_{1}\right), \\
\alpha_{2}=\left(1-u_{A} K_{2}\right)\left(1-K_{2}\right) / u_{A}\left(K_{2}-K_{1}\right),
\end{gathered}
$$

and where $0 \leq K_{1}<v_{A}$ and $0 \leq K_{2}<v_{A}$ and $K_{1} \neq K_{2}$.

In this method, a unit loss is liquidated by means of an infinite sequence of payments $\left\{\left(\alpha_{1} K_{1}^{j}-\alpha_{2} K_{2}^{j}\right) u_{A}^{j}, j=0,1, \ldots\right\}$ and is paid off in perpetuity since

$$
\sum_{j=0}^{\infty}\left(\alpha_{1} K_{1}^{j}-\alpha_{2} K_{2}^{j}\right) u_{A}^{j} \cdot v_{A}^{j}=\frac{\alpha_{1}}{1-K_{1}}-\frac{\alpha_{2}}{1-K_{2}}=1 .
$$

Replacing $S_{t}$ from equation (36) into equation (9) and using equation (12) yields

$$
\left(U L_{t+1}-U_{t+1}\right)-u_{A}\left(U L_{t}-U_{t}\right)=L_{t+1}-u_{A} \sum_{j=0}^{\infty}\left(\alpha_{1} K_{1}^{j}-\alpha_{2} K_{2}^{j}\right) u_{A}^{j} L_{t-j} .
$$


Now define

$$
\begin{aligned}
& \beta_{1}=\left(1-u_{A} K_{1}\right) / u_{A}\left(K_{2}-K_{1}\right), \\
& \beta_{2}=\left(1-u_{A} K_{2}\right) / u_{A}\left(K_{2}-K_{1}\right) .
\end{aligned}
$$

Noting that $\alpha_{1}=\beta_{1}\left(1-K_{1}\right)$ and $\alpha_{2}=\beta_{2}\left(1-K_{2}\right)$ and $\beta_{1}-\beta_{2}=1$, the right hand side of equation (40) may be rewritten as

$$
\begin{aligned}
L_{t+1}+u_{A} \sum_{j=0}^{\infty}\left(\beta_{1} K_{1}^{j+1}-\beta_{2} K_{2}^{j+1}\right) u_{A}^{j} L_{t-j}-u_{A} \sum_{j=0}^{\infty}\left(\beta_{1} K_{1}^{j}-\beta_{2} K_{2}^{j}\right) u_{A}^{j} L_{t-j} \\
=u_{A} \sum_{j=-1}^{\infty}\left(\beta_{1} K_{1}^{j+1}-\beta_{2} K_{2}^{j+1}\right) u_{A}^{j} L_{t-j}-u_{A} \sum_{j=0}^{\infty}\left(\beta_{1} K_{1}^{j}-\beta_{2} K_{2}^{j}\right) u_{A}^{j} L_{t-j} \\
=\sum_{j=0}^{\infty}\left(\beta_{1} K_{1}^{j}-\beta_{2} K_{2}^{j}\right) u_{A}^{j} L_{t+1-j}-u_{A} \sum_{j=0}^{\infty}\left(\beta_{1} K_{1}^{j}-\beta_{2} K_{2}^{j}\right) u_{A}^{j} L_{t-j},
\end{aligned}
$$

which, upon comparison with the left hand side of equation (40), yields

$$
U L_{t}-U_{t}=\sum_{j=0}^{\infty}\left(\beta_{1} K_{1}^{j}-\beta_{2} K_{2}^{j}\right) u_{A}^{j} L_{t-j}
$$

Compare equations (15), (22) and (44).

Under the method of equation (36), for a unit loss that emerged $j$ years ago, the following sequence of payments is yet to be made: $\left\{\left(\alpha_{1} K_{1}^{l}-\alpha_{2} K_{2}^{l}\right) u_{A}^{l}\right.$, $l=j, j+1, \ldots\}$. The present value of these outstanding payments is therefore

$$
\sum_{l=j}^{\infty}\left(\alpha_{1} K_{1}^{l}-\alpha_{2} K_{2}^{l}\right) u_{A}^{l} \cdot v_{A}^{l-j}=\left[\frac{\alpha_{1} K_{1}^{j}}{1-K_{1}}-\frac{\alpha_{2} K_{2}^{j}}{1-K_{2}}\right] u_{A}^{j}=\left(\beta_{1} K_{1}^{j}-\beta_{2} K_{2}^{j}\right) u_{A}^{j} .
$$

Equation (44) thus shows that, at any time $t$, the unfunded liability is the present value of payments yet to be made in respect of all past and present losses, together with the unamortized part of the initial unfunded liability.

The following proposition is proven in the Appendix.

Proposition 1 Provided that

$$
\begin{gathered}
\min \left(i, i_{A}\right)>-100 \%, \\
i-i_{A}<100 \%+i_{A}, \\
0 \leq \min \left(K_{1}, K_{2}\right)<\max \left(K_{1}, K_{2}\right)<\min \left(v, v_{A}\right),
\end{gathered}
$$

then

$$
\lim _{t \rightarrow \infty} L_{t}=-A L\left(i-i_{A}\right) v
$$




$$
\begin{gathered}
\lim _{t \rightarrow \infty} U L_{t}=0, \\
\lim _{t \rightarrow \infty} S_{t}=A L\left(v-v_{L}\right) .
\end{gathered}
$$

The sufficient conditions (46)-(48) in Proposition 1 are not very restrictive. (Necessary and sufficient conditions are discussed in the Appendix.) Condition (46) is easily satisfied under normal economic conditions. Condition (47) also holds in practice. Long-run economic growth means that the actuarial assumption $i_{A}$ as to the long-term rate of return on plan assets is positive $\left(i_{A}>0\right)$. Condition (47) then requires that the actuarial investment return assumption $i_{A}$ does not underestimate the actual return on assets $i$ by $100 \%$ or more. Condition (48) is also easily met in practice. For example, if $\max \left(i, i_{A}\right)=15 \%$, then $0 \leq K_{1}<0.87$ and $0 \leq K_{2}<0.87$ with $K_{1} \neq K_{2}$ means that condition (48) holds.

Corollary 3 Assume that conditions (46)-(48) hold. Then, $\lim U L_{t}=0$, irrespective of whether $i_{A}=i$ or $i_{A}>i$ or $i_{A}<i$.

Compare Corollaries 1, 2 and 3. Corollary 3 states that, under the modified spreading funding method described by equation (36), the pension plan is fully funded in the long term, irrespective of the deviation of the investment return assumption from the actual return on the pension plan assets (provided that the mild conditions (46)-(48) hold). Furthermore, $\lim U L_{t}$ is independent of the funding method parameters $K_{1}$ and $K_{2}$.

The choice of $i_{A}$ affects the progression of funding in the short term, but $i_{A}$ does not affect the funding position asymptotically. In fact, one could arbitrarily set $i_{A}=i_{L}$ as under the classical actuarial valuation methodology described in section 2 and effectively dispense with an investment return assumption $i_{A}$ that is distinct from the rate $i_{L}$ at which the pension liability is valued.

Corollary 3 may be explained as follows. Suppose that a constant stream of intervaluation losses of size $\ell=0$ occurs in the pension plan. Recall that this results in a persisting deficit when losses are being either amortized or spread: see equations (34) and (35) respectively. By contrast, under the method of equation (36), a constant stream of losses of size $\ell \neq 0$ results in zero unfunded liability because, from equation (44) and for $t \geq n$,

$$
U L_{t}=\ell \sum_{j=0}^{\infty}\left(\beta_{1} K_{1}^{j}-\beta_{2} K_{2}^{j}\right) u_{A}^{j}=\ell\left[\frac{\beta_{1}}{1-u_{A} K_{1}}-\frac{\beta_{2}}{1-u_{A} K_{2}}\right]=0
$$

where we use equations (41) and (42).

It was shown that the spreading method of equation (20) could be calculated more directly in terms of the unfunded liability, in equation (23). This may also be achieved here. The following proposition is proven in the Appendix. 
PROPOSITION 2 The funding method described in equation (36) is equivalently achieved by calculating supplementary contributions as follows:

$$
S_{t}=\lambda_{1}\left(U L_{t}-U_{t}\right)+\lambda_{2} \sum_{j=0}^{\infty}\left(U L_{t-j}-U_{t-j}\right)+\left(v_{A}-v_{L}\right) A L+P_{t},
$$

where $\lambda_{1}=1-u_{A} K_{1} K_{2}$ and $\lambda_{2}=v_{A}\left(1-u_{A} K_{1}\right)\left(1-u_{A} K_{2}\right)$.

Trowbridge and Farr (1976, p. 62) state that "easy computations" are a desirable characteristic of a funding method. Equation (53) provides a straightforward way of computing contributions from year to year as only the historic sum of unfunded liabilities need be stored and updated.

Compare equations (23) and (53). The second term on the right hand side of equation (53) represents a historic sum (without interest) of past unfunded liabilities. Contributions are therefore paid until surpluses and deficits cancel each other out and the unfunded liability is zero. Modified spreading of gains and losses, in the representation of equation (53), is similar to a method described by Balzer (1982) in the context of a general insurance system (see also Taylor, 1987). Balzer (1982) refers to a summation term similar to the second term on the right hand side of equation (53) as supplying an "integral action" which adjusts for a "persisting stream of unpredicted claims".

\section{NumericAl EXAMPLE}

An illustration of the previous results is given here and is based on the following:

Demographic projections: Mortality: English Life Table No. 12 (males). Plan population: stationary with single entry age of 20 and single retirement age of 65 .

Salary: Constant throughout working lifetime.

Benefit: A level pension at age 65 paying 2/3 of annual salary.

Economic projections: No inflation. Assets earn a constant rate of return of 4.5\%. Initial unfunded liability: Zero. (Alternatively, assume that $U L_{0}$ is being separately amortized as in equation (10) and that $U L_{t}-U_{t}$, rather than $U L_{t}$ is evaluated below.)

Actuarial valuations: Frequency: yearly. Actuarial cost method: unit credit. Actuarial assumptions: Fixed with valuation assumptions $i_{L}=4 \%, i_{A}=1 \%$, $4.5 \%$ and $6 \%$. Other valuation assumptions are identical to projection assumptions.

Valuation data: Number of entrants and payroll are calculated such that the yearly benefit outgo $B$ is normalized to 1 . Actuarial liability $A L=16.94$, normal cost $N C=0.3486$, both expressed as a proportion of $B$.

Funding method parameters: Amortization: $m=5$. Spreading: $K=1-1 / \ddot{a}_{\overline{5}}$. Modified spreading: $K_{1}=K, K_{2}=0.8$.

When $i=i_{A}=4.5 \%$, numerical work (not shown here) shows that neither gain nor loss arises and the funded ratio (that is, ratio of fund value to actuarial 


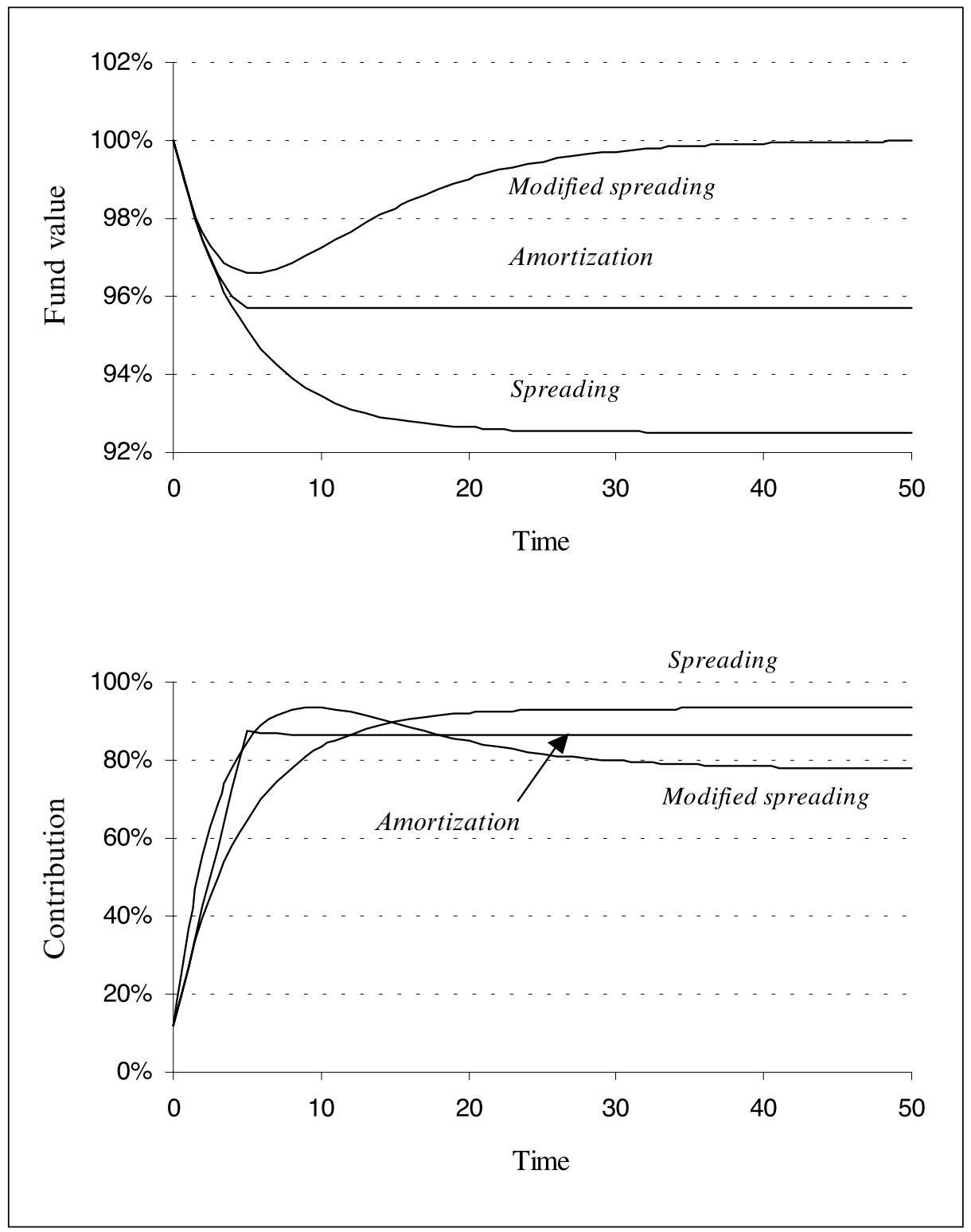

Figure 1: Fund value (per cent of actuarial liability) and contribution (per cent of normal cost) against time (years) when $i_{A}=6 \%$ and $i=4.5 \%$ for amortization, spreading and modified spreading.

liability) remains at $100 \%$, while the contribution paid is equal to the normal cost, for all three methods. This accords with Corollaries 1,2 and 3 when $i_{A}=i$.

When $i=4.5 \%$ and $i_{A}=6 \%$, the investment return assumption is optimistic. Fund values (as a percentage of actuarial liability) and contributions (as a percentage of normal cost) over time are exhibited in Table 1. See also Figure 1. 


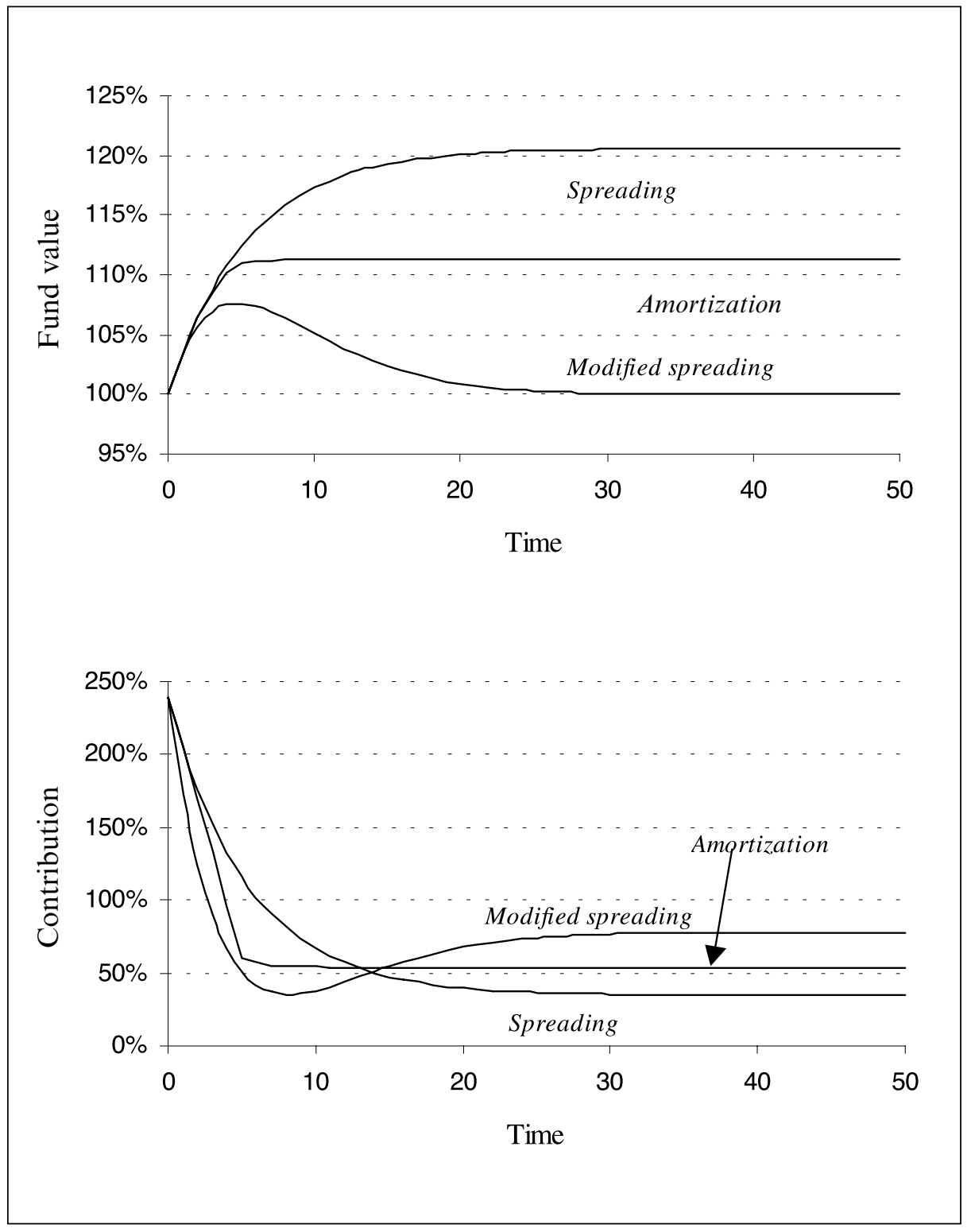

Figure 2: Fund value (per cent of actuarial liability) and contribution (per cent of normal cost) against time (years) when $i_{A}=1 \%$ and $i=4.5 \%$ for amortization, spreading and modified spreading.

A contribution that is equal to $11.8 \%$ of normal cost is required initially under all three methods. Under amortization, the required contribution levels off at $86.6 \%$ of normal cost and an unfunded liability of $4.3 \%$ of actuarial liability remains. Under spreading, the contribution rises steadily to $93.3 \%$ of normal cost and an unfunded liability of $7.5 \%$ of actuarial liability is left eventually. 
TABLE 1

FUND VALUE (PER CENT OF ACTUARIAL LIABILITY) AND CONTRIBUTION (PER CENT OF NORMAL COST) WHEN $i_{A}=6 \%$ AND $i=4.5 \%$ FOR AMORTIZATION $(A)$, SPREADING $(S)$ AND MODIFIED SPREADING $(M S)$.

\begin{tabular}{rrrrrcr}
\hline \hline Time & \multicolumn{3}{c}{ Fund value (\%) } & & & Contribution (\%) \\
& $\mathbf{A}$ & $\mathbf{S}$ & MS & $\mathbf{A}$ & $\mathbf{S}$ & MS \\
\hline 0 & 100.0 & 100.0 & 100.0 & 11.8 & 11.8 & 11.8 \\
2 & 97.4 & 97.4 & 97.6 & 42.5 & 39.7 & 55.6 \\
4 & 96.0 & 95.8 & 96.7 & 72.5 & 58.1 & 78.2 \\
6 & 95.7 & 94.6 & 96.6 & 87.0 & 70.1 & 88.8 \\
8 & 95.7 & 93.9 & 96.8 & 86.6 & 78.1 & 92.9 \\
10 & 95.7 & 93.4 & 97.2 & 86.6 & 83.3 & 93.4 \\
12 & 95.7 & 93.1 & 97.7 & 86.6 & 86.7 & 92.3 \\
14 & 95.7 & 92.9 & 98.1 & 86.6 & 89.0 & 90.5 \\
16 & 95.7 & 92.8 & 98.4 & 86.6 & 90.5 & 88.4 \\
18 & 95.7 & 92.7 & 98.8 & 86.6 & 91.4 & 86.5 \\
20 & 95.7 & 92.6 & 99.0 & 86.6 & 92.1 & 84.8 \\
25 & 95.7 & 92.6 & 99.5 & 86.6 & 92.9 & 81.7 \\
30 & 95.7 & 92.5 & 99.7 & 86.6 & 93.2 & 79.8 \\
35 & 95.7 & 92.5 & 99.8 & 86.6 & 93.3 & 78.8 \\
40 & 95.7 & 92.5 & 99.9 & 86.6 & 93.3 & 78.3 \\
45 & 95.7 & 92.5 & 100.0 & 86.6 & 93.3 & 78.0 \\
50 & 95.7 & 92.5 & 100.0 & 86.6 & 93.3 & 77.8 \\
\hline \hline
\end{tabular}

TABLE 2

FUND VALUE (PER CENT OF ACTUARIAL LIABILITY) AND CONTRIBUTION (PER CENT OF NORMAL COST) WHEN $i_{A}=1 \%$ AND $i=4.5 \%$ FOR AMORTIZATION $(A)$, SPREADING $(S)$ AND MODIFIED SPREADING $(M S)$.

\begin{tabular}{rcccrrr}
\hline \hline Time & \multicolumn{3}{c}{ Fund value (\%) } & & \multicolumn{3}{c}{ Contribution (\%) } \\
& $\mathbf{A}$ & $\mathbf{S}$ & MS & $\mathbf{A}$ & $\mathbf{S}$ & MS \\
\hline 0 & 100.0 & 100.0 & 100.0 & 238.8 & 238.8 & 238.8 \\
2 & 106.3 & 106.3 & 105.7 & 169.1 & 175.9 & 124.1 \\
4 & 110.2 & 110.7 & 107.5 & 96.5 & 132.3 & 66.3 \\
6 & 111.2 & 113.8 & 107.3 & 57.1 & 102.2 & 41.7 \\
8 & 111.2 & 115.9 & 106.3 & 54.6 & 81.3 & 35.2 \\
10 & 111.3 & 117.3 & 105.1 & 54.1 & 66.9 & 37.7 \\
12 & 11.3 & 118.3 & 103.8 & 54.1 & 56.9 & 44.0 \\
14 & 111.3 & 119.0 & 102.8 & 54.1 & 50.0 & 51.2 \\
16 & 11.3 & 119.5 & 102.0 & 54.1 & 45.3 & 57.8 \\
18 & 111.3 & 119.9 & 101.3 & 54.1 & 42.0 & 63.4 \\
20 & 111.3 & 120.1 & 100.9 & 54.1 & 39.7 & 67.7 \\
25 & 111.3 & 120.4 & 100.3 & 54.1 & 36.6 & 74.2 \\
30 & 111.3 & 120.5 & 100.1 & 54.1 & 35.3 & 76.7 \\
35 & 111.3 & 120.6 & 100.0 & 54.1 & 34.9 & 77.5 \\
40 & 111.3 & 120.6 & 100.0 & 54.1 & 34.7 & 77.7 \\
45 & 111.3 & 120.6 & 100.0 & 54.1 & 34.6 & 77.7 \\
50 & 111.3 & 120.6 & 100.0 & 54.1 & 34.5 & 77.7 \\
\hline \hline
\end{tabular}


Under modified spreading, the required contribution stabilizes at about 78\% of normal cost with the plan being fully funded eventually. This therefore agrees with Corollaries 1, 2 and 3 when $i_{A}>i$ : long-run deficits occur under amortization and spreading, but not under modified spreading. Furthermore, numerical experiments suggest that the long-run unfunded liabilities that occur under amortization and spreading are larger, the larger the deviation between actual and assumed returns.

Note that the pension fund is ultimately in balance under all three methods. For example, under amortization, using units of yearly benefit outgo, a fund of $95.7 \% \times 16.94=16.21$ yields investment income of $16.21 \times 4.5 \%=0.7295$ at the end of the year. At the start of the year, the present value of this income is $0.7295 / 1.045=0.698$. Contribution income is $86.6 \% \times 0.3486=0.301$. Total income is $0.698+0.301=1$ which balances the benefit of 1 that is paid out. The balance occurs at different levels under the three methods. Under modified spreading, the fund is eventually in equilibrium in such a way that the pension plan is fully funded.

When $i=4.5 \%$ and $i_{A}=1 \%$, a conservative investment return assumption is being made. See Table 2 and Figure 2. A large contribution (more than double the normal cost) is required initially under all three funding methods. Intervaluation gains lead initially to falling contributions under all three methods (at about the same rate). Ultimately, the lowest contribution (at only 35\% of normal cost) is generated when spreading is used, but this is at the expense of a large surplus in the pension fund of $20 \%$ of actuarial liability. On the other hand, the surplus is only $5 \%$ of actuarial liability within 10 years, and under $1 \%$ within 20 years, when modified spreading is used. This also agrees with Corollaries 1, 2 and 3 when $i_{A}<i$.

\section{CONCLUSION}

The investment return assumption made by actuaries when valuing defined benefit pension plans and its relevance to the pace of funding for pension benefits was discussed in section 2 . It was argued that this assumption is theoretically distinct from the discount rate that is used to value pension liabilities, although they may be equal in practice. A simplified model pension plan was posited in Section 3, where actuarial liability, normal cost and benefit outgo were constant. The only intervaluation gains and losses allowed in the model resulted from actual investment return deviating from the actuarial investment return assumption.

Two practical funding methods were described in sections 4 and 5 and it was shown, in both cases, that a conservative investment return assumption leads to a long-term surplus whereas an optimistic investment return assumption leads to a long-term deficit. Both long-term surpluses and deficits were deemed to be undesirable. Surpluses may entail expensive demands for benefit enhancements from plan members during wage negotiations and also involves the diversion of capital away from projects within the sponsoring corporation. Deficits may endanger the security of pension benefits should the plan sponsor 
become insolvent. A funding method was devised and described in section 6 that avoids such persistent surpluses and deficits, under mild stability conditions, independently of the conservatism or optimism in the actuarial investment return assumption. A simple way of implementing this funding method was derived in terms of the historic sum of past unfunded liabilities. A numerical illustration of these results was provided in section 7 .

The analysis in this paper yielded closed-form mathematical solutions but this required simplistic modelling assumptions. Future research should relax these restrictive assumptions. First, only asset gains and losses were considered. Mortality, withdrawal, inflation and other factors are also variable and should be incorporated in the model. Second, these factors are uncertain and intervaluation gains and losses are random. A stochastic approach following Dufresne $(1988,1989)$ and Owadally and Haberman (1999), who investigate pension funding with random investment returns, should be illuminating. It will enable a more realistic comparison of the various funding methods to be made in terms of the variance of fund values and contributions. The efficient choice of parameters $K_{1}$ and $K_{2}$ under modified spreading of gains and losses can also then be investigated.

\section{ACKNOWLEDGEMENT}

The author would like to thank Steve Haberman for his comments on this paper. 


\section{Appendix}

\section{Proof of Proposition 1}

It is easy to show, from equations (37), (38), (41) and (42) that

$$
\begin{gathered}
\alpha_{1}-\alpha_{2}=1+v_{A}-K_{1}-K_{2}, \\
\alpha_{1} K_{2}-\alpha_{2} K_{1}=v_{A}-K_{1} K_{2}, \\
\beta_{1}-\beta_{2}=1, \\
\beta_{1} K_{2}-\beta_{2} K_{1}=v_{A} .
\end{gathered}
$$

Replace $S_{t}$ from equation (36) and $U L_{t}$ from equation (44) into equation (8), and use equation (12), to obtain:

$$
L_{t+1}=\left(i-i_{A}\right)\left[\sum_{j=0}^{\infty}\left[\left(\beta_{1}-\alpha_{1}\right) K_{1}^{j}-\left(\beta_{2}-\alpha_{2}\right) K_{2}^{j}\right] u_{A}^{j} L_{t-j}-v_{A}\left(A L-U_{t+1}\right)\right] .
$$

This may be rewritten using the lag or backward shift operator $B$ as follows:

$$
B^{-1} L_{t}=\left(i-i_{A}\right)\left[\frac{\beta_{1}-\alpha_{1}}{1-u_{A} K_{1} B} L_{t}-\frac{\beta_{2}-\alpha_{2}}{1-u_{A} K_{2} B} L_{t}-B^{-1} v_{A}\left(A L-U_{t}\right)\right] .
$$

Note from equations (54)-(57) that

$$
\begin{gathered}
\left(\beta_{1}-\alpha_{1}\right)-\left(\beta_{2}-\alpha_{2}\right)=K_{1}+K_{2}-v_{A}, \\
\left(\beta_{1}-\alpha_{1}\right) K_{2}-\left(\beta_{2}-\alpha_{2}\right) K_{1}=K_{1} K_{2} .
\end{gathered}
$$

Multiply both sides of equation (59) by $\left(1-u_{A} K_{1} B\right)\left(1-u_{A} K_{2} B\right) B$ and use the two equations above:

$$
\begin{aligned}
\left(1-u_{A} K_{1} B\right)\left(1-u_{A} K_{2} B\right) L_{t}=\left(i-i_{A}\right) & {\left[\left(K_{1}+K_{2}-v_{A}\right) B L_{t}-u_{A} K_{1} K_{2} B^{2} L_{t}\right.} \\
- & \left.\left(1-u_{A} K_{1} B\right)\left(1-u_{A} K_{2} B\right) v_{A}\left(A L-U_{t}\right)\right] .
\end{aligned}
$$

Collect terms in $L_{t}$ on the left hand side to obtain a second order linear difference equation for $L_{t}$ :

$$
\begin{aligned}
\left\{1-B\left[u K_{1}+u K_{2}-u v_{A}+1\right]\right. & \left.+B^{2}\left[u u_{A} K_{1} K_{2}\right]\right\} L_{t} \\
= & -\left(1-u_{A} K_{1} B\right)\left(1-u_{A} K_{2} B\right) v_{A}\left(i-i_{A}\right)\left(A L-U_{t}\right) .
\end{aligned}
$$

Difference equation (63) has a quadratic characteristic equation,

$$
P(z)=z^{2}-z\left[u K_{1}+u K_{2}-u v_{A}+1\right]+u u_{A} K_{1} K_{2}=0,
$$


whose roots must be less than one in magnitude for $\left\{L_{t}\right\}$ to converge as $t \rightarrow \infty$. Necessary and sufficient conditions for this for a general quadratic equation are given by Marden (1966):

$$
\begin{aligned}
|P(0)|<1 & \Rightarrow\left|u u_{A} K_{1} K_{2}\right|<1, \\
P(1)>0 & \Rightarrow u v_{A}\left(1-u_{A} K_{1}\right)\left(1-u_{A} K_{2}\right)>0, \\
P(-1)>0 & \Rightarrow u v_{A}\left[2 u_{A}\left(v+u_{A} K_{1} K_{2}\right)-\left(1-u_{A} K_{1}\right)\left(1-u_{A} K_{2}\right)\right]>0 .
\end{aligned}
$$

It is now shown that inequalities (65)-(67) follow from the sufficient conditions in Proposition 1. Note first that condition (46) may be rewritten as $0<\min \left(u, u_{A}\right) \leq$ $\max \left(u, u_{A}\right)$. Conditions (46) and (48) thus imply that

$$
0 \leq \min \left(u, u_{A}\right) \min \left(K_{1}, K_{2}\right)<\max \left(u, u_{A}\right) \max \left(K_{1}, K_{2}\right)<1 .
$$

Hence, inequality (65) follows from sufficient conditions (46) and (48).

Next, note from the inequalities (68) that

$$
0<1-\max \left(u, u_{A}\right) \max \left(K_{1}, K_{2}\right)<1-\min \left(u, u_{A}\right) \min \left(K_{1}, K_{2}\right) \leq 1,
$$

and therefore that

$$
0<\left(1-u_{A} K_{1}\right) \leq 1 \text { and } 0<\left(1-u_{A} K_{2}\right) \leq 1 .
$$

Hence, inequality (66) follows from sufficient conditions (46) and (48).

Finally, condition (47) may be written as $u<2 u_{A}$ or $2 u_{A} v>1$, by virtue of condition (46). It follows from inequalities (70) that

$$
\begin{gathered}
\left(1-u_{A} K_{1}\right)\left(1-u_{A} K_{2}\right) \leq 1<2 u_{A} v \leq 2 u_{A} v+2 u_{A}^{2} K_{1} K_{2} \\
\Rightarrow 2 u_{A}\left(v+u_{A} K_{1} K_{2}\right)-\left(1-u_{A} K_{1}\right)\left(1-u_{A} K_{2}\right)>0 .
\end{gathered}
$$

Hence, inequality (67) follows from sufficient conditions (46), (47) and (48).

Let the roots of the characteristic equation (64) be $\nu_{1}$ and $\nu_{2}$. If $\nu_{1} \neq \nu_{2}$, $L_{t}$ in equation (63) has a solution of the form $L_{t}=A \nu_{1}^{t}+B \nu_{2}^{t}+L$, where $A$, $B, L \in \mathbb{R}$. If sufficient conditions (46)-(48) hold, then $\left|\nu_{1}\right|<1$ and $\left|\nu_{2}\right|<1$, the sequence $\left\{L_{t}\right\}$ converges to $L$ and, furthermore, the series $\sum_{j=0}^{\infty}\left(L_{j}-L\right)$ is absolutely convergent.

Assuming convergence, it is clear from equation (63) that

$$
\begin{aligned}
L=\lim _{t \rightarrow \infty} L_{t} & =\frac{-\left(1-u_{A} K_{1}\right)\left(1-u_{A} K_{2}\right) v_{A}\left(i-i_{A}\right) A L}{1-\left[u K_{1}+u K_{2}-u v_{A}+1\right]+\left[u u_{A} K_{1} K_{2}\right]} \\
& =-A L\left(i-i_{A}\right) v \frac{v_{A}\left(1-u_{A} K_{1}\right)\left(1-u_{A} K_{2}\right)}{v_{A}\left(1-u_{A} K_{1}\right)\left(1-u_{A} K_{2}\right)}=-A L\left(i-i_{A}\right) v,
\end{aligned}
$$

which proves equation (49). 
The limit in equation (51) is obtained by resorting to equation (36):

$$
\begin{aligned}
S_{t}=\sum_{j=0}^{\infty}\left(\alpha_{1} K_{1}^{j}-\alpha_{2} K_{2}^{j}\right) u_{A}^{j}\left(L_{t-j}-L\right)+\sum_{j=0}^{\infty} & \left(\alpha_{1} K_{1}^{j}-\alpha_{2} K_{2}^{j}\right) u_{A}^{j} L \\
& +\left(v_{A}-v_{L}\right) A L+P_{t} .
\end{aligned}
$$

As $t \rightarrow \infty$, the first sum on the right hand side of equation (74) vanishes since both $\sum_{j=0}^{\infty}\left(\alpha_{1} K_{1}^{j}-\alpha_{2} K_{2}^{j}\right) u_{A}^{j}$ and $\sum_{j=0}^{\infty}\left(L_{j}-L\right)$ are absolutely convergent and their Cauchy product is also absolutely convergent. As $t \rightarrow \infty$, the second sum on the right hand side of equation (74) converges to

$$
\left(\frac{\alpha_{1}}{1-u_{A} K_{1}}-\frac{\alpha_{2}}{1-u_{A} K_{2}}\right) \times L=v_{A} \times-A L\left(i-i_{A}\right) v=-A L\left(v_{A}-v\right),
$$

where use is made of equations (37) and (38). $P_{t}$ also vanishes as $t \rightarrow \infty$ from equation (10). Hence, $\lim _{t \rightarrow \infty} S_{t}=-A L\left(v_{A}-v\right)+A L\left(v_{A}-v_{L}\right)=A L\left(v-v_{L}\right)$.

Finally, the limit in equation (50) is obtained by taking limits on each term on the right hand side of equation (44) which may be rewritten as follows:

$$
U L_{t}-U_{t}=\sum_{j=0}^{\infty}\left(\beta_{1} K_{1}^{j}-\beta_{2} K_{2}^{j}\right) u_{A}^{j}\left(L_{t-j}-L\right)+\sum_{j=0}^{\infty}\left(\beta_{1} K_{1}^{j}-\beta_{2} K_{2}^{j}\right) u_{A}^{j} L .
$$

As $t \rightarrow \infty$, the first sum on the right hand side of equation (76) vanishes since both $\sum_{j=0}^{\infty}\left(\beta_{1} K_{1}^{j}-\beta_{2} K_{2}^{j}\right) u_{A}^{j}$ and $\sum_{j=0}^{\infty}\left(L_{j}-L\right)$ are absolutely convergent and their Cauchy product is also absolutely convergent. As $t \rightarrow \infty$, the second sum on the right hand side of equation (76) converges to zero since

$$
\sum_{j=0}^{\infty}\left(\beta_{1} K_{1}^{j}-\beta_{2} K_{2}^{j}\right) u_{A}^{j}=\frac{\beta_{1}}{1-u_{A} K_{1}}-\frac{\beta_{2}}{1-u_{A} K_{2}}=0,
$$

where use is made of equations (41) and (42). Hence, $\lim _{t \rightarrow \infty} U L_{t}=0$.

\section{Proof of Proposition 2}

Rewrite equation (44) in terms of the lag or backward shift operator $B$ :

$$
\begin{aligned}
U L_{t}-U_{t} & =\left[\frac{\beta_{1}}{1-u_{A} K_{1} B}-\frac{\beta_{2}}{1-u_{A} K_{2} B}\right] L_{t} \\
& =\frac{\left(\beta_{1}-\beta_{2}\right)-\left(\beta_{1} K_{2}-\beta_{2} K_{1}\right) u_{A} B}{\left(1-u_{A} K_{1} B\right)\left(1-u_{A} K_{2} B\right)} L_{t} .
\end{aligned}
$$

Using equations (56) and (57), the numerator on the right hand side of the above equation simplifies and

$$
U L_{t}-U_{t}=\frac{1-B}{\left(1-u_{A} K_{1} B\right)\left(1-u_{A} K_{2} B\right)} L_{t} .
$$


Likewise, rewrite equation (36) in terms of the backward shift operator $B$ and use equations (54) and (55) to simplify:

$$
\begin{aligned}
S_{t} & =\left[\frac{\alpha_{1}}{1-u_{A} K_{1} B}-\frac{\alpha_{2}}{1-u_{A} K_{2} B}\right] L_{t}+\left(v_{A}-v_{L}\right) A L+P_{t} \\
& =\frac{\left(1+v_{A}-K_{1}-K_{2}\right)-\left(v_{A}-K_{1} K_{2}\right) u_{A} B}{\left(1-u_{A} K_{1} B\right)\left(1-u_{A} K_{2} B\right)} L_{t}+\left(v_{A}-v_{L}\right) A L+P_{t} .
\end{aligned}
$$

Cancel $L_{t}$ from equations (79) and (80) and simplify:

$$
\begin{aligned}
S_{t} & -\left(v_{A}-v_{L}\right) A L-P_{t} \\
& =\frac{\left(1+v_{A}-K_{1}-K_{2}\right)-\left(v_{A}-K_{1} K_{2}\right) u_{A} B}{1-B}\left(U L_{t}-U_{t}\right) \\
& =\left[1-u_{A} K_{1} K_{2}+\frac{v_{A}\left(1-u_{A} K_{1}\right)\left(1-u_{A} K_{2}\right)}{1-B}\right]\left(U L_{t}-U_{t}\right) \\
& =\left(1-u_{A} K_{1} K_{2}\right)\left(U L_{t}-U_{t}\right)+v_{A}\left(1-u_{A} K_{1}\right)\left(1-u_{A} K_{2}\right) \sum_{j=0}^{\infty}\left(U L_{t-j}-U_{t-j}\right),
\end{aligned}
$$

which is equation (53).

\section{REFERENCES}

Actuarial Standards BoArd (1996) Actuarial Standard of Practice No. 27: Selection of Economic Assumptions for Measuring Pension Obligations. Pensions Committee of the Actuarial Standards Board, American Academy of Actuaries, Washington, DC.

BALZER, L.A. (1982) Control of insurance systems with delayed profit/loss-sharing feedback and persisting unpredicted claims. Journal of the Institute of Actuaries 109, 285-316.

Berin, B.N. (1989) The Fundamentals of Pension Mathematics. Society of Actuaries, Schaumburg, Illinois.

DAYKIN, C.D. (1976) Long-term rates of interest in the valuation of a pension fund. Journal of the Institute of Actuaries 21, 286-340.

Dufresne, D. (1988) Moments of pension contributions and fund levels when rates of return are random. Journal of the Institute of Actuaries 115, 535-544.

DufRESNE, D. (1989) Stability of pension systems when rates of return are random. Insurance: Mathematics and Economics 8, 71-76.

Marden, M. (1966) The Geometry of Polynomials, 2nd ed. American Mathematical Society, Providence, Rhode Island.

McGill, D.M., Brown, K.N., Haley, J.J. and Schieber, S.J. (1996) Fundamentals of Private Pensions, 7th ed. University of Pennsylvania Press, Philadelphia, Pennsylvania.

Owadally, M.I. and Haberman, S. (1999) Pension fund dynamics and gains/losses due to random rates of investment return. North American Actuarial Journal 3(3), 105-117.

TAYLOR G.C. (1987) Control of unfunded and partially funded systems of payments. Journal of the Institute of Actuaries 114, 371-392.

Thornton, P.N. and WiLson, A.F. (1992) A realistic approach to pension funding. Journal of the Institute of Actuaries 119, 229-312. 
Trowbridge, C.L. (1952) Fundamentals of pension funding. Transactions of the Society of Actuaries 4, 17-43.

Trowbridge, C.L. and Farr, C.E. (1976) The Theory and Practice of Pension Funding. Richard D. Irwin, Homewood, Illinois.

M. IQBAL OWADALLY

Faculty of Actuarial Science and Statistics

Cass Business School

City University

106 Bunhill Row, London EC1Y 8TZ, England

Email: iqbal@city.ac.uk 